\title{
Highly efficient small form factor LED retrofit lamp
}

\author{
Final Report
}

Report Period Start Date:

Report Period End Date:

Principal Investigator:

Authors:

DOE Award Number:
October 1, 2009

September 30, 2011

Steven C. Allen

Steven C. Allen,

Fred Palmer and Ming Li

DE-EE0000611

OSRAM SYLVANIA

54 Cherry Hill Dr., Danvers, MA 01923 


\section{DISCLAIMER}

This report was prepared as an account of work sponsored by an agency of the United States Government. Neither the United States Government nor any agency thereof, nor any of their employees, makes any warranty, express or implied, or assumes any legal liability or responsibility for the accuracy, completeness, or usefulness of any information, apparatus, product, or process disclosed, or represents that its use would not infringe privately owned rights. Reference herein to any specific commercial product, process, or service by trade name, trademark, manufacturer, or otherwise does not necessarily constitute or imply its endorsement, recommendation, or favoring by the United States Government or any agency thereof. The views and opinions of authors expressed herein do not necessarily state or reflect those of the United States Government or any agency thereof. 


\section{EXECUTIVE SUMMARY}

This report summarizes work to develop a high efficiency LED-based MR16 lamp downlight at OSRAM SYLVANIA under US Department of Energy contract DE-EE0000611. A new multichip LED package, electronic driver, and reflector optic were developed for these lamps. At steady-state, the lamp luminous flux was 409 lumens (Im), luminous efficacy of 87 lumens per watt (LPW), CRI (Ra) of 87, and R9 of 85 at a correlated color temperature (CCT) of $3285 \mathrm{~K}$. The LED alone achieved 120 lumens per watt efficacy and 600 lumen flux output at $25^{\circ} \mathrm{C}$. The driver had $90 \%$ electrical conversion efficiency while maintaining excellent power quality with power factor $>0.90$ at a power of only 5 watts. Compared to similar existing MR16 lamps using LED sources, these lamps had much higher efficacy and color quality. 


\section{TABLE OF CONTENTS}

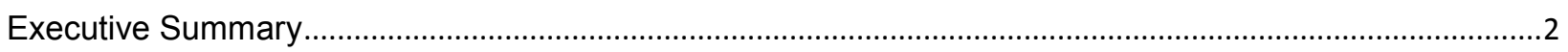

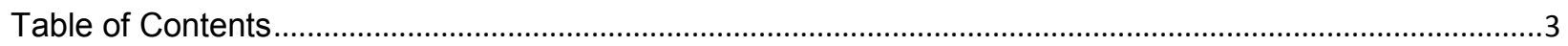

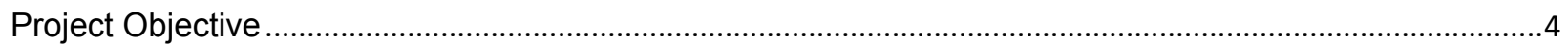

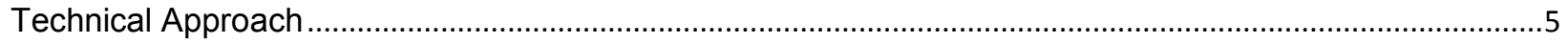

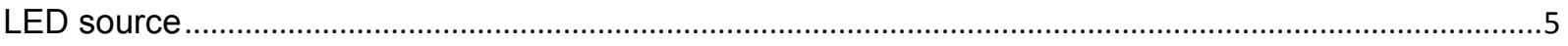

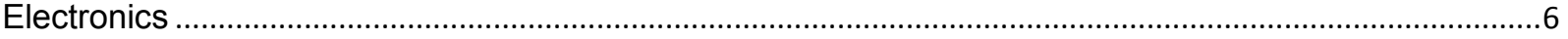

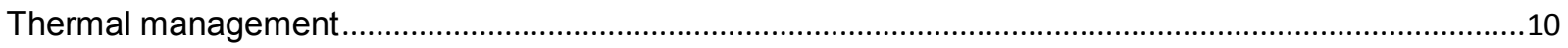

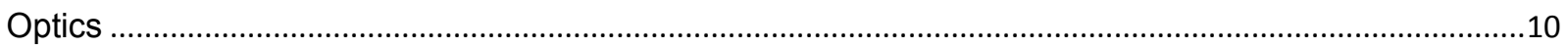

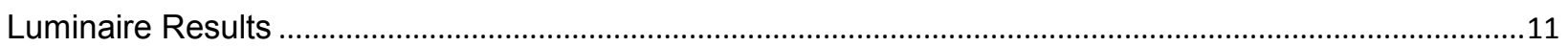

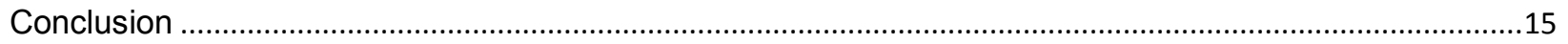

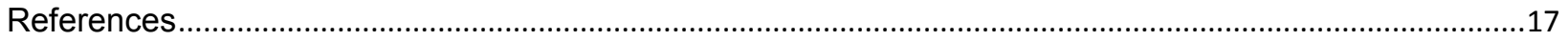




\section{PROJECT OBJECTIVE}

The objective of this work was to demonstrate a LED-based MR16 retrofit lamp for replacement of 35W halogen MR16 lamps having (1) luminous flux of 500 lumens, (2) luminous efficacy of 100 lumens per watt, (3) beam angle less than $40^{\circ}$ and center beam candlepower of at least 1000 candelas, and (4) excellent color quality.

(1) Luminous flux of $\mathbf{5 0 0}$ lumens. Approximate lumens equivalent to a $35 \mathrm{~W}$ halogen MR16 lamp and 2-5X greater than available MR16 LED lamps.

(2) $\mathbf{1 0 0}$ lumens per watt steady-state luminaire efficacy. To reach this level of performance, a combination of $\sim 140$ LPW LED source and luminaire efficiency of $72 \%$ was proposed. The luminaire efficiency includes electrical, thermal, and optical losses.

(3) Center beam candlepower (CBCP) of $1000 \mathrm{~cd}$.

(4) Excellent color quality. Defined as having a correlated color temperature (CCT) between 2700 and $3500 \mathrm{~K}$, a color rendering index $\left(R_{a}\right)$ of $\geq 85$, and an $R 9$ (deep red color rendering) $\geq 50$.

At the time of the proposal, the $73 \%$ luminaire efficiency was the DOE MYPP goal for year $2012^{1}$ :

Table 1. Proposed performance.

\begin{tabular}{|l|c|c|c|}
\hline & $\begin{array}{c}\text { Proposed } \\
\text { OSI MR16 }\end{array}$ & $\begin{array}{c}\text { DOE } \\
\text { MYPP }\end{array}$ & $\begin{array}{c}\text { DOE } \\
\text { MYPP }\end{array}$ \\
\hline Year & 2011 & 2010 & 2012 \\
\hline Warm white device efficacy $\left(\mathrm{Im} / \mathrm{W}, \mathbf{2 5}^{\circ} \mathrm{C}\right)$ & 140 & 122 & 139 \\
\hline Thermal efficiency & $88 \%$ & $89 \%$ & $91 \%$ \\
\hline Driver efficiency & $90 \%$ & $89 \%$ & $91 \%$ \\
\hline Fixture efficiency & $90 \%$ & $84 \%$ & $88 \%$ \\
\hline Resultant lamp efficiency & $72 \%$ & $66 \%$ & $73 \%$ \\
\hline Resultant lamp/luminaire efficacy $(\mathrm{Im} / \mathrm{W})$ & 101 & 81 & 101 \\
\hline
\end{tabular}
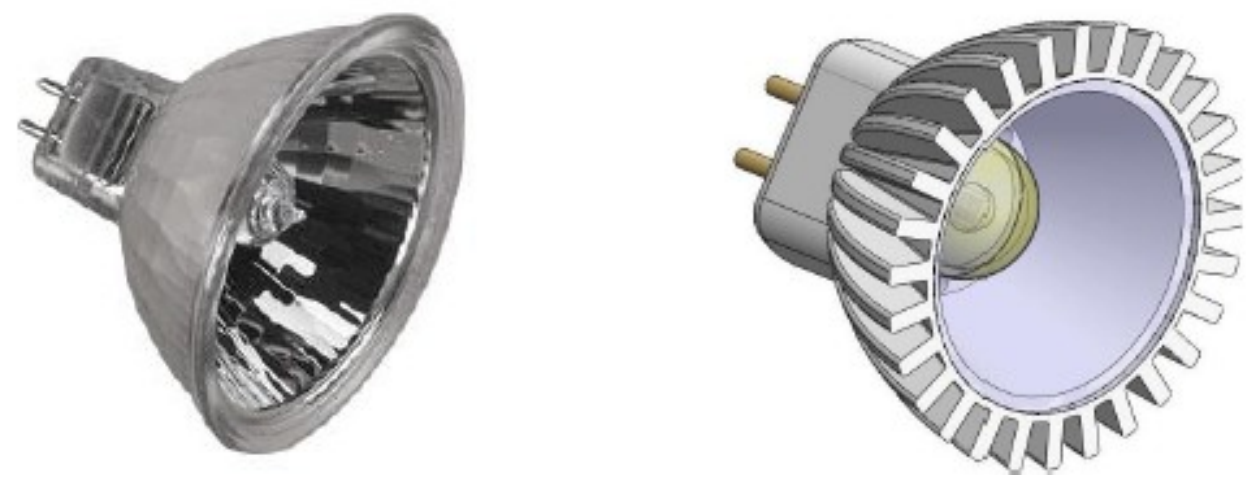

Figure 1. Halogen MR16 lamp (left) and CAD rendering of proposed luminaire (right). 


\section{TECHNICAL APPROACH}

\section{LED SOURCE}

Design of the LED source was driven by 3 needs: (1) high efficacy (2) excellent color rendering and (3) small size to accommodate collimation optics within the diminutive MR16 form factor. OSRAM's Brilliant Mix ${ }^{2}$ approach of combining phosphor converted InGaN greenish white (called EQ white) and InGaAIP amber LEDs was chosen for its combination of high efficacy and excellent color rendering.

Both luminous efficacy and color quality are of high importance in this application, so a combination of greenish white and amber dies was chosen to maximize luminous efficacy while meeting CRI requirements. An array of individual packaged LEDs such as OSLONs would be too large for the MR16. While the array can physically fit inside the lamp dimensions, a collimating optic necessary to achieve $<40^{\circ}$ FWHM would be larger than the maximum lamp dimensions. A solution to this is a multichip package containing both LED colors.

A unique arrangement of LED chips consisting of three $1 \mathrm{~mm}$ EQ white and nine $0.5 \mathrm{~mm}(0.25 \mathrm{~mm})$ amber chips was designed in a single package as shown in Figure 2.

The LED consisted of the following components:

(1) Ceramic circuit board. Aluminum nitride with thin film metallization on both sides.

(2) LED chips. Three $1 \mathrm{~mm}^{2}$ blue LED chips and nine $0.25 \mathrm{~mm}^{2}$ amber chips supplied by OSRAM Opto Semiconductors.

(3) Phosphor converters. Blend of phosphor powders in clear silicone for conversion of blue LED light to a greenish white color.

(4) Clear silicone encapsulation. Protects LED chips and wire bonds. Also maximizes light extraction from LED chips.

(5) Zener diodes. Provides protection from reverse polarity and electrostatic discharges.

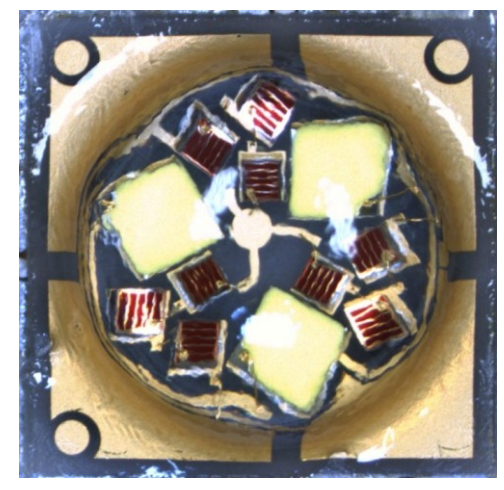

Figure 2. Photograph of LED developed for the MR16 lamp.

The LED was initially tested at $25^{\circ} \mathrm{C}$ using pulsed current measurements at $1 \%$ duty cycle. Driving the EQ white at $350 \mathrm{~mA}$ and the amber at $117 \mathrm{~mA}$ resulted in on-Planckian CCT of approximately $3100 \mathrm{~K}$, luminous efficacy of 
120LPW, CRI of 88 , and R9 of 60 . As the $\mathrm{T}_{\mathrm{j}}$ increases toward the steady-state lamp value, on-Planckian CCT and R9 tend to increase, CRI remains relatively unchanged, and luminous efficacy decreases.

The LED uses blue die having 55\% electrical to optical efficiency; the project goals were based on having blue die with $70 \%$ efficiency. If such dies were available, LED efficacy would increase to 144 LPW at 25C, 350mA.

\section{ELECTRONICS}

The driver is required to support two color mixing while maintaining a small form factor. A novel "buck or boost" topology was developed to meet these requirements.

\section{(1) Color control}

The MR-16 lamp runs on 12VAC. In order to save space and promote longevity, we have full-wave rectified this voltage and used it directly, without any large smoothing capacitor. The load for the driver consists of three mint LED's in series ( 3.3 volts each for a total of 10 volts) and a $3 \times 3$ array of amber (red) LED's (7 volts total). If the mint and amber groups carry the same current, the resulting color is too red, so the amber chips must operate on reduced current or a shorter duty cycle. Furthermore, the brightness of the amber LED's varies significantly with temperature, so the amber power needs to be adjusted during warm-up. Balancing the mint and amber output could be accomplished with two controllers, but this is unfavorable in terms of both cost and space. This driver operates by dividing each AC half-cycle into a part when both mint and amber arrays carry the same current, and a part when only the mint LED's are on. All this is done without using a microcontroller.

The LED arrangement is shown on the right hand side of Figure 3. Current is supplied to the mint string, after which it either goes through the amber array, or through the transistor to ground. The switching is controlled by an oscillator that is synchronized with the input power. The output of the oscillator is shaped into a triangular wave, which is compared with a reference voltage. The relevant voltages are shown in Figure 4 . When the triangle wave is higher than the reference, the transistor is closed and both the mint and amber LED's operate. The rest of the time, the ambers are shorted out and only the mints are on.

The reference voltage is supplied by a voltage divider that includes an NTC thermister mounted on the LED board. As the temperature rises, the reference voltage drops, causing the amber LED's to be on longer. (In earlier versions, no oscillator was used in this circuit, and the incoming rectified sine wave was used in place of the triangle wave. We replaced this design because it was hard to control when the amber-on times were short, and because the lamp color tended to be influenced by power supply characteristics.) 


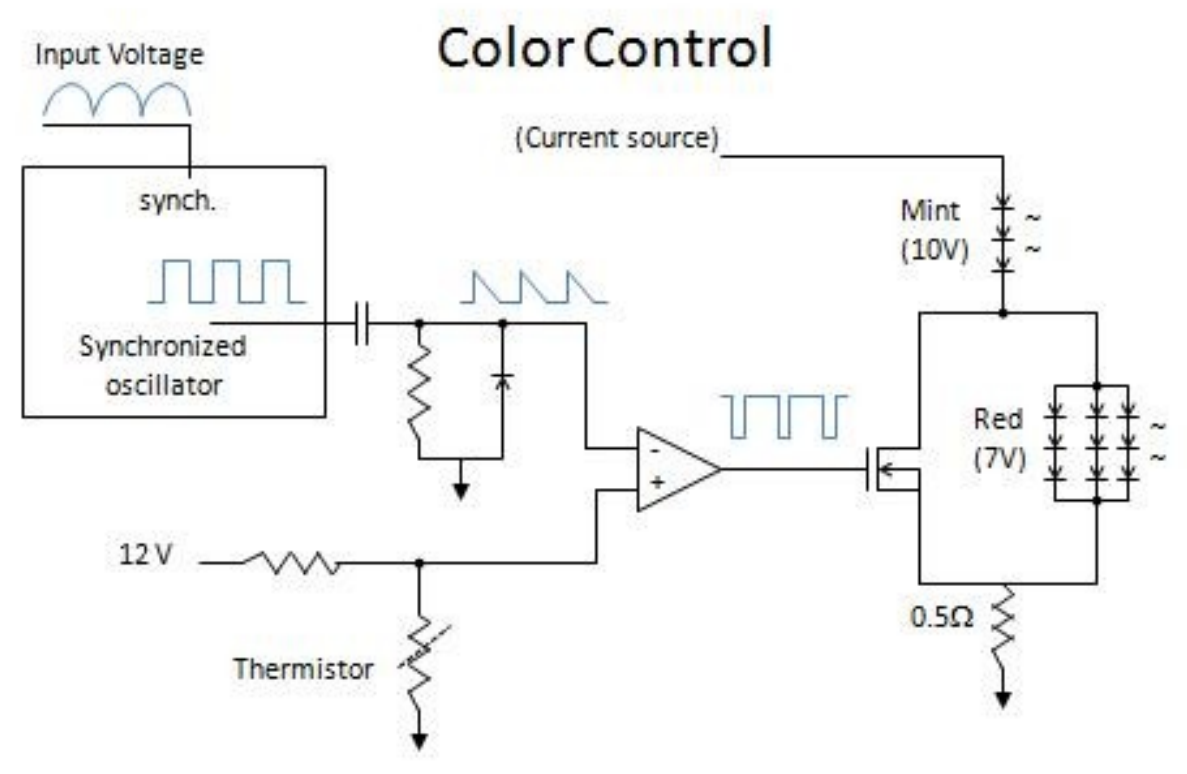

Figure 3. Color control unit in power supply.

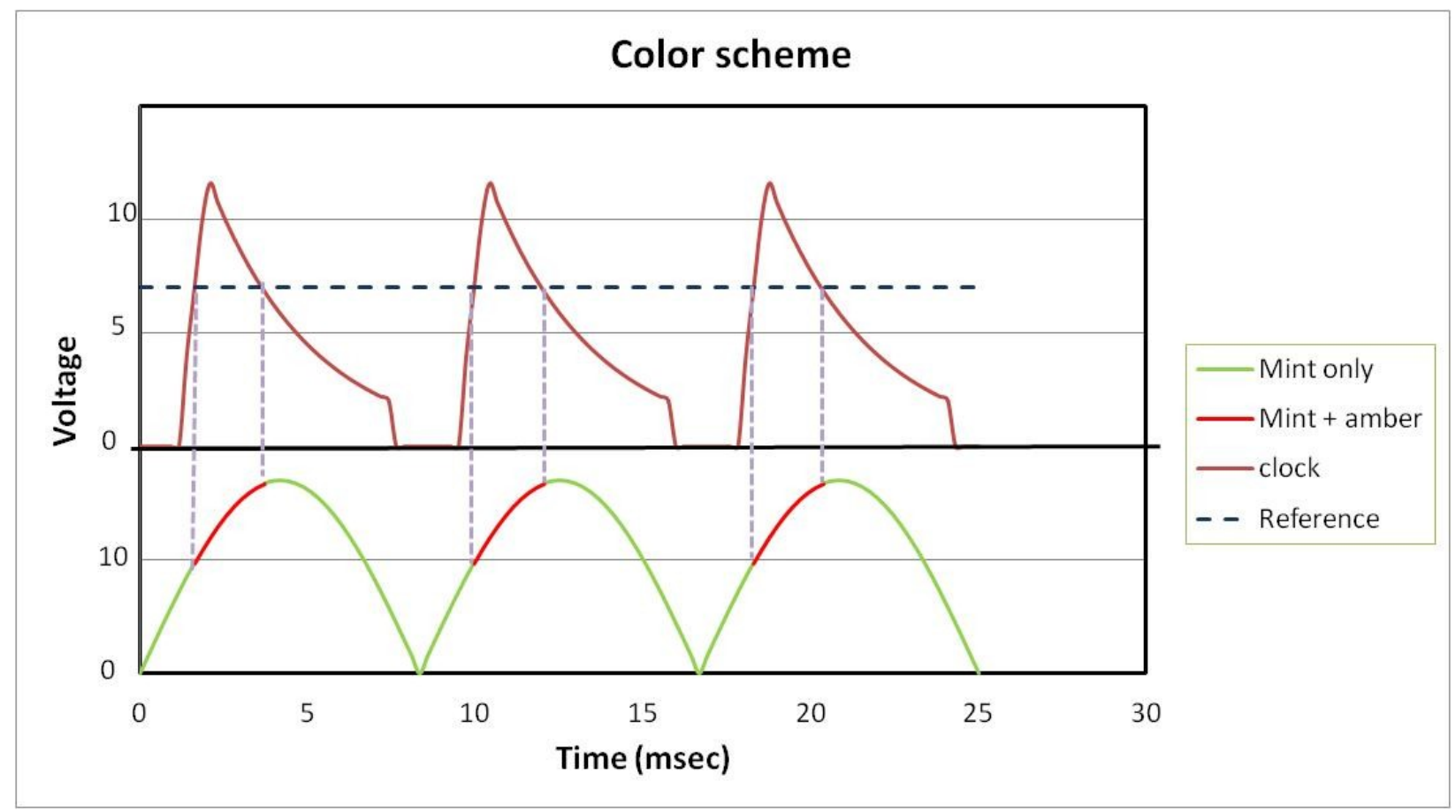

Figure 4. Color control scheme.

(2) "Buck or boost" driver 
During the time when amber LED's are turn on, the overall voltage drop of the light engine is $~ 15-16 \mathrm{~V}$, but when they are off, this number becomes $\sim 9-10 \mathrm{~V}$. The input to the driver, however, is a rectified sine wave that varies between zero and $17 \mathrm{~V}$. Consequently, the load voltage is sometimes higher and sometimes lower than the input voltage. This presents a challenge for the driver. A new topology, called "buck or boost" topology, is used to meet this challenge. It extends the capability of the controller to drive both buck and boost transistors.

A block diagram is shown in Figure 5. If the input voltage is higher than the output, the transistor Q2 is kept open (non conducting) and Q1 is pulsed on and off to control the current through the inductor. In the opposite case, Q1 is continually conducting, and Q2 is pulsed to maintain current flow. The controller chip (TPS40211) is designed to control Q2. We have extended it to control Q1, using the clock and error-amplifier pins on the chip. The voltage on the clock pin is a saw tooth, oscillating between about 0.2 and 1 volt. The error amplifier monitors the current through the LED's. If the current is too large, the error amplifier voltage goes down; if too small it goes up. During regular boost operation, the error amplifier stays at about 3 volts, but if the input voltage exceeds the load voltage, the LED current rises and the error amplifier quickly falls into the 0 to 1 volt range. The comparator then sends pulses to Q1, which takes over the regulation of the current. The error amplifier is now doing three things. It performs its usual function in the controller, regulating the boost (Q2) transistor; it switches modes of operation; and it regulates the buck transistor (Q1) when needed.

\section{Buck or Boost}

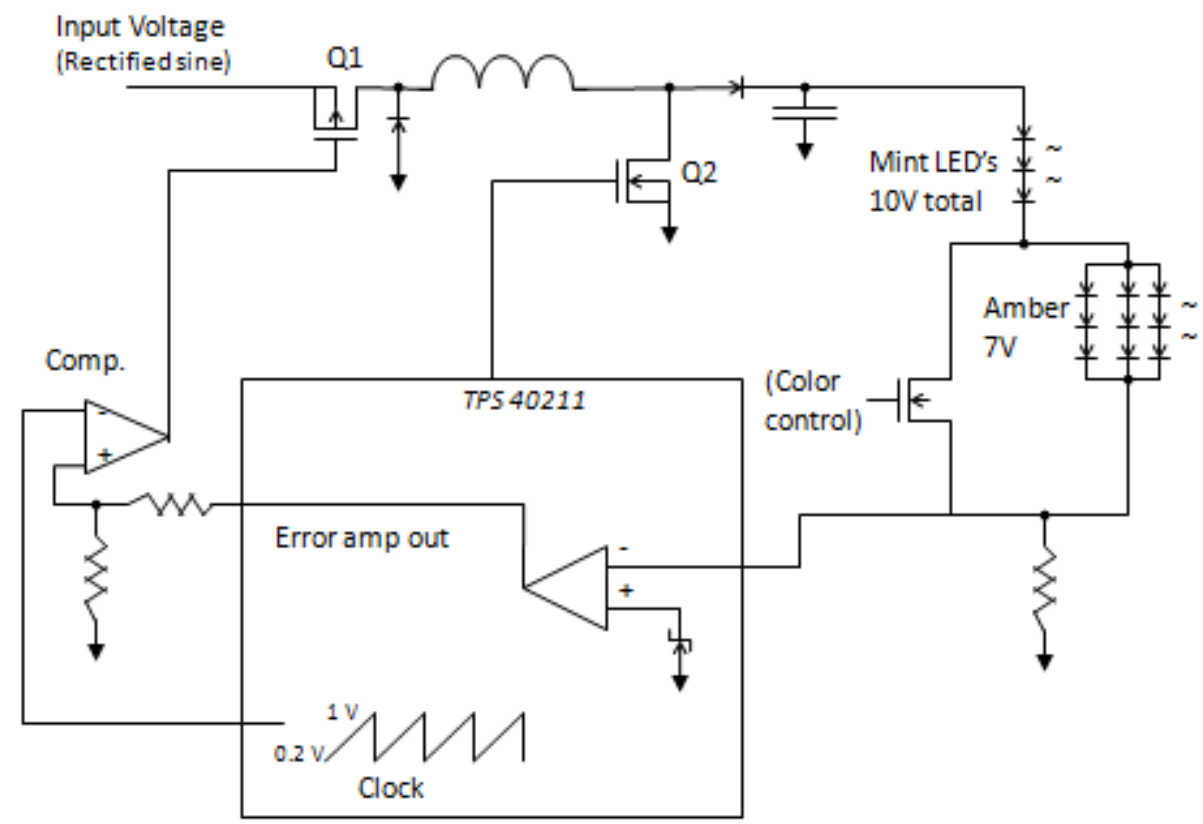

Figure 5. "Buck" or "boost" driver.

A power factor correction circuit is necessary in order to keep the controller from attempting to power the LED's when the input voltage is very low. The input voltage from the bridge is a rectified sine wave that is fed into an inverting amplifier. The inverted voltage is then added to the voltage on the controller feedback pin. Depending on how high this pin is, the controller will send little or no current to the LED's

\section{(3) Energy Storage}


We have also investigated an optional energy storage system. Storage improves the lamp efficacy by reducing the peak current through the LED's, making up the lost lumens by supplying some current during the time when there is little or no input voltage. The circuit is shown in Figure 6. The capacitors and diodes are arranged in a "valley fill" circuit that connects the capacitors in series when charging, and in parallel when discharging. If connected directly across the rectified input, the valley fill circuit supplies stored energy to the system only when the input voltage is less than one half of its peak value. However, the FET bridge is incompatible with storage capacitors. It drains the capacitors back into the power line when the input voltage is zero. Consequently, transistors are used to switch the input back and forth between the bridge and the capacitors. Using a 200 microfarad bank of ceramic capacitors for each of the capacitors shown in the figure is sufficient to improve the efficacy by about 5 percent, but this feature still requires about 16 components, half of which are the capacitors, about $3 \times 3 \times 3 \mathrm{~mm}$ in size.

\section{Energy Storage}

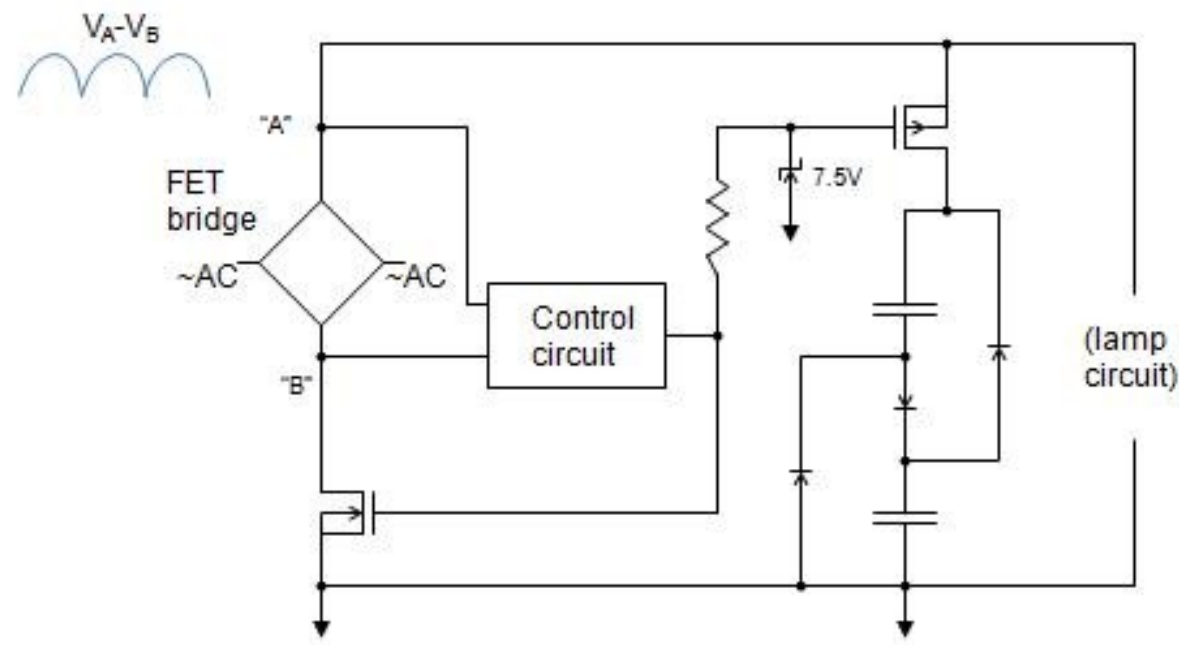

Figure 6. Optional energy storage unit.

\section{(4) Electronic driver Performance}

Table 1. Driver targets and actual performance. 


\begin{tabular}{|l|c|c|c|c|}
\hline & $\begin{array}{c}\text { Electrical } \\
\text { efficiency } \\
\text { (Pout/Pin) }\end{array}$ & $\begin{array}{c}\text { Power } \\
\text { Factor }\end{array}$ & $\begin{array}{c}\text { Run on both 12 V } \\
\text { AC and DC }\end{array}$ & $\begin{array}{c}\text { Off state } \\
\text { power } \\
\text { consumption }\end{array}$ \\
\hline Project Goal & $90 \%$ & 0.90 & Yes & 0 watt \\
\hline $\begin{array}{l}\text { Actual } \\
\text { performance }\end{array}$ & $91 \%$ & 0.92 & Yes & 0 watt \\
\hline
\end{tabular}

\section{THERMAL MANAGEMENT}

Throughout the lamp, components were chosen for good thermal performance. Keeping the LED junction temperatures low is critical to high efficacy at steady-state because the InGaAIP LED flux rapidly decreases with increasing temperature as shown in Figure 7.

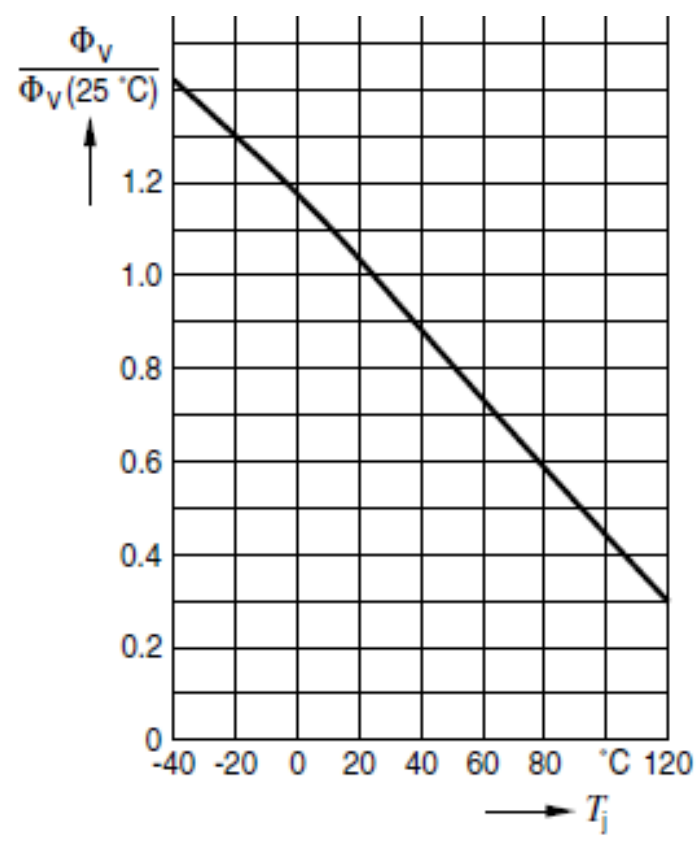

Figure 7. Relative luminous flux versus temperature for amber LEDs. From OSRAM Opto Semiconductors ${ }^{3}$.

Thermal management efforts were focused on two critical areas, the heat sink and LED substrate. For the heat sink, the design strategy involved maximizing the surface area of each fin while staying within the allowed MR16 lamp dimensions, finding the optimum number of fins, and anodizing external surfaces for maximum radiation. Aluminum nitride was selected for the LED substrate material because of its superior thermal conductivity.

With an input power of $5.0 \mathrm{~W}$, the LED solder point temperature was $68^{\circ} \mathrm{C}$ and the temperature between heat sink fins was $65^{\circ} \mathrm{C}$ at steady-state. Junction temperature was estimated to be approximately $10^{\circ}$ higher than the solder point temperature.

\section{OPTICS}


The role of the fixture optics is to convert the emitted light from the LED to the desired far-field distribution. At minimum, the fixture optics must achieve a beam angle FWHM of $\leq 40^{\circ}$ and $\mathrm{CBCP}$ of at least $1000 \mathrm{~cd}$. Other factors such as visual appearance, cutoff angle, and total size were also considered.

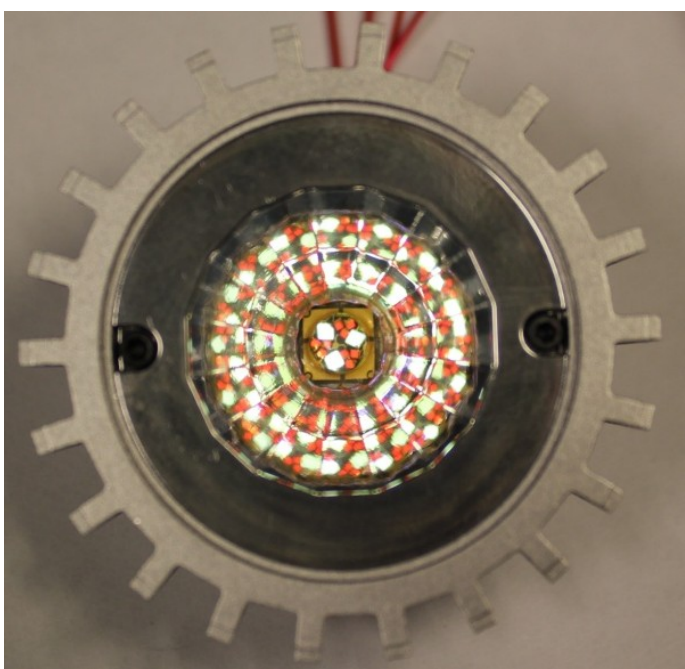

Figure 8. Photographs of the lamp with a metalized reflector optic. The diffuser cover is removed for clarity.

Metalized reflector solution. A metalized reflector was the initial optic of choice because temperatures were expected to be too high for acrylic. Square facets were added to the reflector profile to maximize color mixing uniformity in the far field. Beam FWHM as low as 26 degrees was demonstrated with optical efficiencies ranging from 82 to $87 \%$, depending on the diffuser used.

Acrylic TIR reflector solution. When it became clear that lamp operating temperature was low enough, an acrylic TIR optic was developed. Like the metalized reflector, the sidewalls were faceted for maximum color mixing uniformity. Beam FWHM as low as $18^{\circ}$ were obtained with a CBCP of $1600 \mathrm{~cd}$. The typical efficiency was $93 \%$, significantly higher than the metalized reflector. All reported lamp results use acrylic TIR optics.

\section{LAMP RESULTS}

An integrated MR16 lamp prototype was completed. It incorporated the high efficiency color mixing LEDs and driver previously reported, a new TIR optic, and new heat sink.
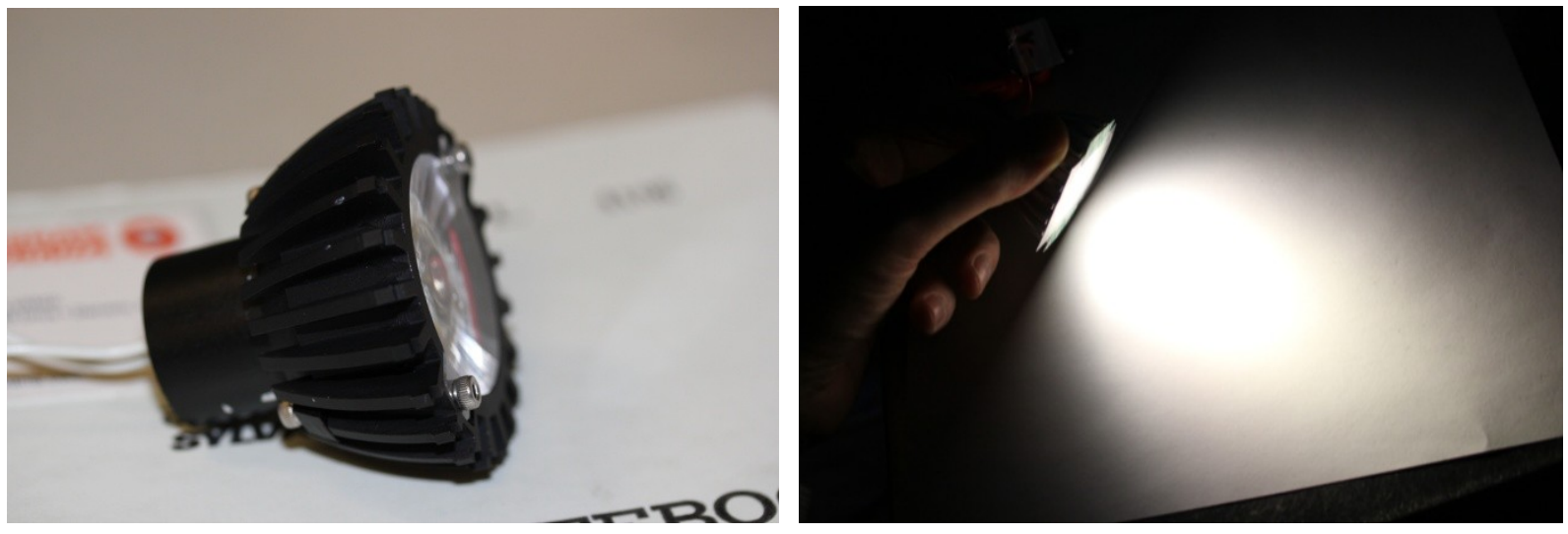
Figure 9. Lamp photographs. Lamp as used for results shown in Table 4 (left); similar lamp with light diffuser sheet added for better color mixing (right).

Photometric measurements were made in a $1 \mathrm{~m}$ integrating sphere. Nine MR16 lamps were tested: including 4 halogens, 3 currently on the market LED-based, lamps, and two developed at OSRAM SYLVANIA (OSI) under this work. The halogens included a $20 \mathrm{~W}$, two $35 \mathrm{~W}$ and a $50 \mathrm{~W}$ to demonstrate typical luminous efficacy and flux values used in the application. All lamps were powered by a $12 \mathrm{VAC} 60 \mathrm{~Hz}$ sine wave. All lamps except the OSI MR16 were measured after only a few seconds of on time to minimize thermal effects. The OSI lamp was run "hot" at approximately its operation temperature, but not at "steady-state" because the driver was an unoptimized prototype not stable at the desired power of $5 \mathrm{~W}$ and on-Planck chromaticity point.

Table 3. Lamp photometric performance. The halogens and competitor LED lamps were measured after a few seconds of on time; the OSI LED lamps were at steady-state.

\begin{tabular}{|l|c|c|c|c|c|c|c|c|c|c|}
\cline { 2 - 11 } & \multicolumn{4}{|c|}{ Halogen lamps } & \multicolumn{3}{c|}{ On-market competitors } & \multicolumn{2}{c|}{ OSI--this work } \\
\hline & $\mathbf{2 0 W}$ & $\mathbf{3 5 W}$ & $\mathbf{3 5 W}$ & $\mathbf{5 0 W}$ & $\mathbf{\# 1}$ & $\mathbf{\# 2}$ & $\mathbf{\# 3}$ & \#1 & \#2 \\
\hline & halogen & halogen & halogen & halogen & LED & LED & LED & LED & LED \\
\hline & MR16 & MR16 & MR16 & MR16 & MR16 & MR16 & MR16 & MR16 & MR16 \\
\hline Electrical power (W) & 20 & 35 & 34 & 50 & 4.1 & 6.8 & 3.5 & 5.1 & 4.7 \\
\hline Luminous flux (Im) & 248 & 360 & 422 & 666 & 165 & 218 & 186 & 385 & 409 \\
\hline Luminous efficacy (Im/W) & 12 & 10 & 12 & 13 & 40 & 32 & 53 & 76 & 87 \\
\hline CCT (K) & 2777 & 2847 & 2787 & 2816 & 2970 & 2870 & 3029 & 2816 & 3285 \\
\hline CRI & 99 & 100 & 99 & 100 & 80 & 84 & 83 & 87 & 87 \\
\hline R9 & 99 & 100 & 98 & 99 & 13 & 34 & 28 & 74 & 85 \\
\hline WPE & $10.3 \%$ & $8.3 \%$ & $10.2 \%$ & $10.9 \%$ & $13.3 \%$ & $10.9 \%$ & $17.2 \%$ & $24.2 \%$ & $26.3 \%$ \\
\hline
\end{tabular}

OSI MR16s easily exceeded the LPW of all the competitor lamps, despite the competitive LED lamps being run "cold" after only a few seconds of on time. Luminous efficacy was as follows: 10-13LPW for the four halogen lamps, 32-53LPW for the LED lamps already on the market, and 76 and 87LPW for the two OSI lamps.

Hot luminous flux of the OSI lamps are roughly $2 \mathrm{X}$ the competitor LED lamps, while falling between the two measured 35W halogen lamps. Luminous flux is short of the project goal of 500 lumens, but the intent of the project was to match $35 \mathrm{~W}$ halogen lamp luminous flux, so perhaps the lumen goal is set too high. Competitor MR16 LED lamps had cold luminous flux values even lower than the $20 \mathrm{~W}$ halogen, even though some had packaging claiming equivalence to $35 \mathrm{~W}$ halogen.

The 87 LPW efficacy is $13 \%$ less than the project target of 100 LPW, but the blue LED chips are about $20 \%$ less efficient than anticipated in the proposal (55\% actual WPE vs. $70 \%$ expected WPE).

Color quality for the OSI lamp is excellent and exceeds project targets. CRI is 87 and R9 is 74-85, depending on CCT; project goals are 85 and 50, respectively. Competitor MR16 LED lamps have CRI $\leq 84$ and R9 $\leq 34$, so at least the OSI deep red color rendering is significantly higher.

Goniometry was performed on a lamp identical in construction, but having a CCT of about 3000K and efficacy of about 70LPW. Data is shown in Figures 10 and 11. 


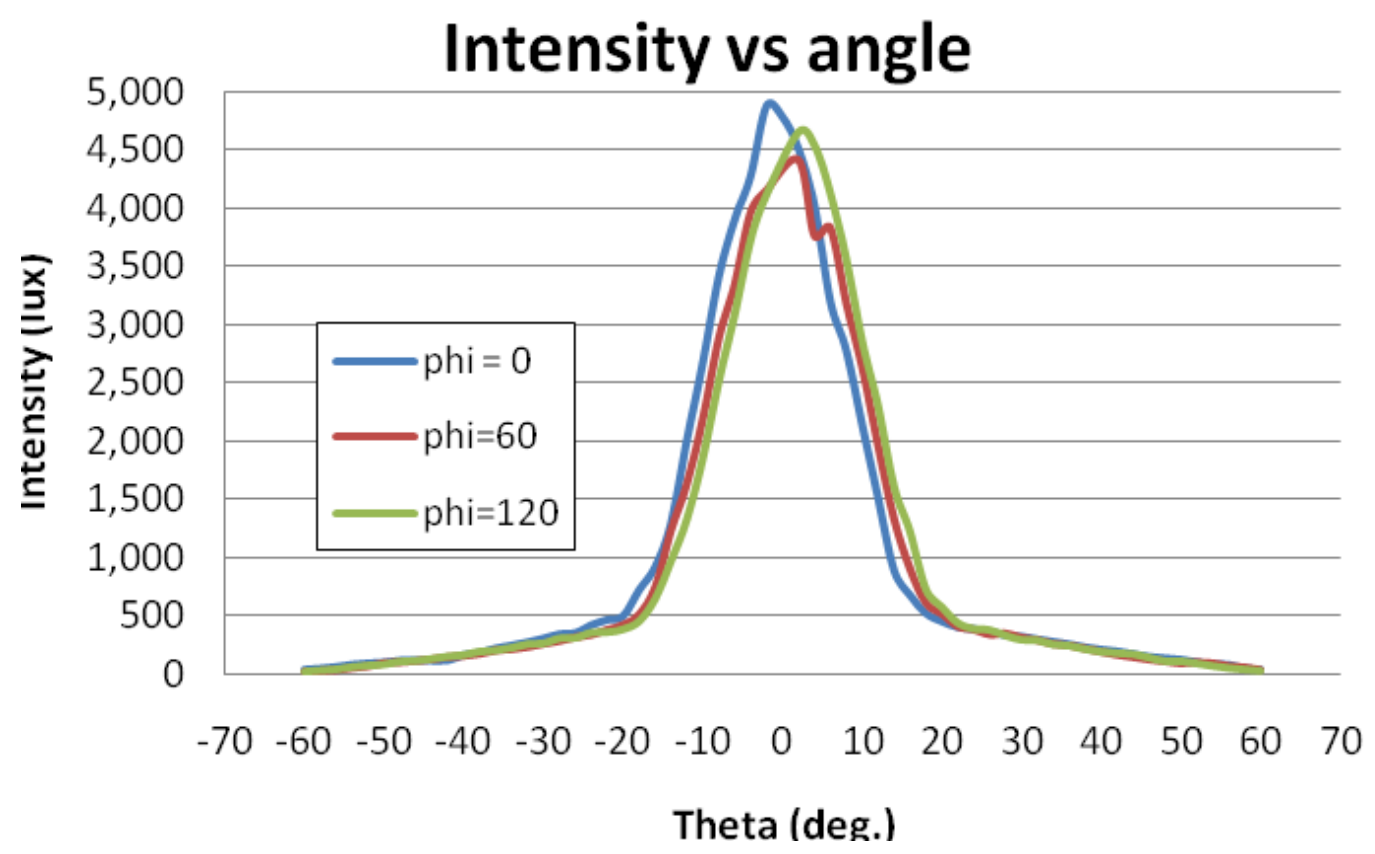

Figure 10. Intensity vs. angle plots for 3 different phi angles. Beam FWHM is 20 degrees, CBCP is over 1100 lumens.

A separate candle power measurement suggests that the central beam candle power is $\sim 1600 \mathrm{~cd}$, which is well above the project goal of $1000 \mathrm{~cd}$.

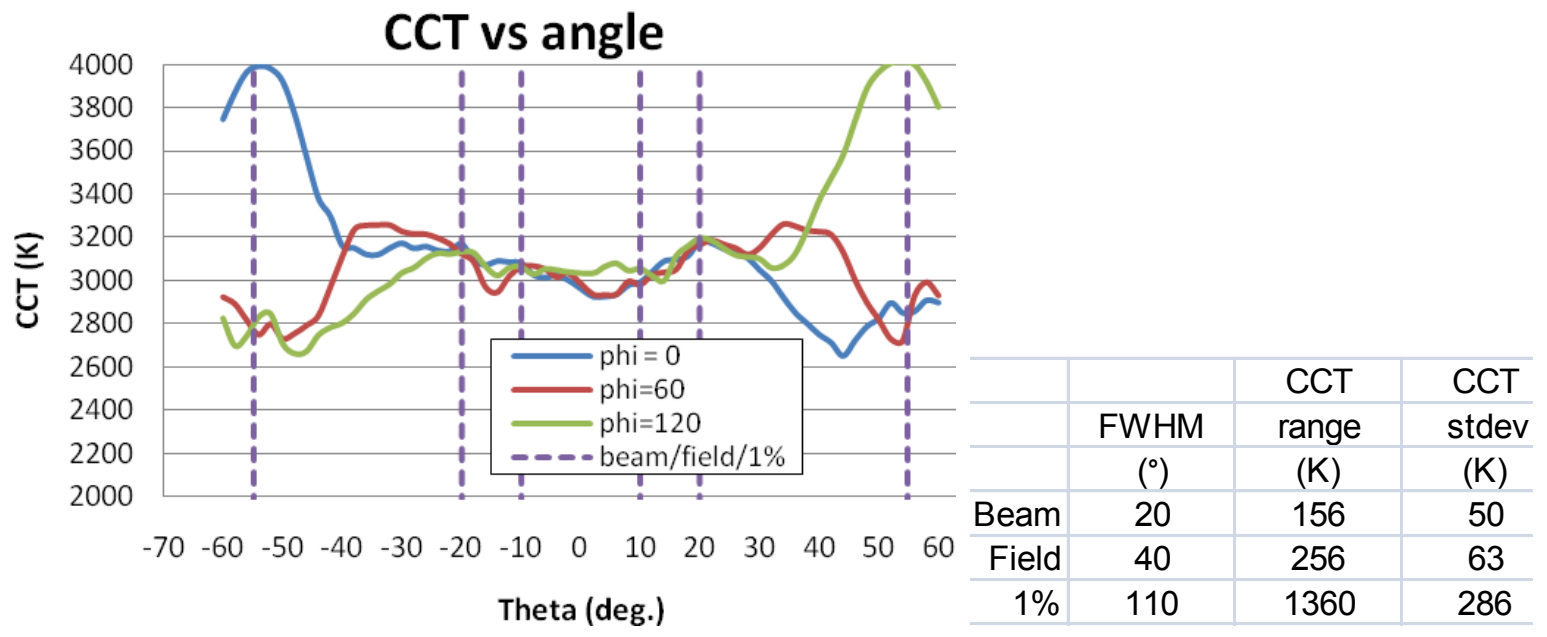

Figure 11. CCT vs. angle for 3 different phi angles (left) and summary of CCT range and standard deviation over beam, field and $1 \%$ intensity angles (right). Note the large amount of color separation that occurs beyond the field angle.

Figure 11 shows CCT variation across the projected beam. Within the beam angle CCT ranged only 156K, which is virtually unnoticeable to the eye; within the field angle CCT ranged 256K, which is slightly visible to the eye. Beyond the field angle where the lamp is quite dim, CCT ranged $1360 \mathrm{~K}$ with alternating regions of greenish white and pinkish white. This may not be acceptable for some applications (such as grazing on a white wall), but can be greatly reduced by adding a mild diffusing sheet on top of the TIR optic with only a few percent loss in efficiency. 
Table 4. Proposed and actual performance of OSI's MR16.

\begin{tabular}{|c|c|c|c|c|}
\hline Metric & $\begin{array}{c}\text { OSI } \\
\text { MR16 } \\
\text { Proposed } \\
\text { in } 2008\end{array}$ & $\begin{array}{c}\text { OSI } \\
\text { MR16 } \\
\text { Achieved } \\
\text { in } 2011\end{array}$ & $\begin{array}{l}\text { DOE } \\
2010\end{array}$ & $\begin{array}{l}\text { DOE } \\
2012\end{array}$ \\
\hline $\begin{array}{l}\text { Blue LED efficiency (Wall Plug } \\
\text { Efficiency) }\end{array}$ & $70 \%$ & $50 \%$ & & \\
\hline Warm white device efficacy $\left(\operatorname{lm} / \mathrm{W}, 25^{\circ} \mathrm{C}\right)$ & 140 & 120 & 122 & 139 \\
\hline Thermal efficiency & $88 \%$ & $85 \%$ & $89 \%$ & $91 \%$ \\
\hline Driver efficiency & $90 \%$ & $91 \%$ & $89 \%$ & $91 \%$ \\
\hline Fixture efficiency & $90 \%$ & $94 \%$ & $84 \%$ & $88 \%$ \\
\hline Resultant lamp efficiency & $72 \%$ & $73 \%$ & $66 \%$ & $73 \%$ \\
\hline Resultant lamp/luminaire efficacy (Im/W) & 101 & 87 & 81 & 101 \\
\hline
\end{tabular}

Table 5. OSI lamp performance before and after 1000 hour burn-in test.

\begin{tabular}{|c|c|c|}
\hline & $\begin{array}{c}t=0 \\
8 / 8 / 11\end{array}$ & $\begin{array}{c}t=1175 \\
\text { hours } \\
9 / 26 / 11\end{array}$ \\
\hline & OSI & OSI \\
\hline & LED & LED \\
\hline & MR16 & MR16 \\
\hline Electrical power (W) & 4.79 & 4.76 \\
\hline Luminous flux (Im) & 372 & 357 \\
\hline $\begin{array}{l}\text { Luminous efficacy } \\
(\operatorname{lm} / \mathrm{W})\end{array}$ & 78 & 75 \\
\hline $\mathrm{CCT}(\mathrm{K})$ & 2885 & 2892 \\
\hline CRI & 85 & 85 \\
\hline $\mathrm{R} 9$ & 74 & 62 \\
\hline CIE X & 0.4328 & 0.4331 \\
\hline CIE Y & 0.3820 & 0.3837 \\
\hline WPE & $21.7 \%$ & $20.9 \%$ \\
\hline
\end{tabular}

\section{CONCLUSION}

The LED MR16 lamps developed here closely match $35 \mathrm{~W}$ halogen luminous flux values while consuming only $5 \mathrm{~W}$ for an energy savings of $85 \%$. Hot luminous efficacies of the lamps were about $2 \mathrm{X}$ higher than the "cold" values of measured on the market LED MR16 lamps. Color quality was excellent and exceeded project targets. The flux and efficacy is below project targets, however, due to the lower blue chip efficiency than anticipated. 
A new multichip warm white LED was developed using two colors and two chip sizes. At $25^{\circ} \mathrm{C}$, the LEDs were capable of 120 LPW efficacy, flux of 540 lumens at $4.5 \mathrm{~W}, \mathrm{CRI}$ of 88 , and R9 of 60 at a CCT of $3100 \mathrm{~K}$.

The driver delivers $92 \%$ efficiency at only $5 \mathrm{~W}$ input power while simultaneously balancing the color of the two LEDs to maintain stable chromaticity with change in temperature. 


\section{REFERENCES}

${ }^{1}$ Multi-Year Program Plan FY'09-FY'14, Solid-State Lighting Research and Development, Prepared for: Lighting Research and Development, Building Technologies Program, Office of Energy Efficiency and Renewable Energy, U.S. Department of Energy. Prepared by Navigant Consulting, Inc., Radcliffe Advisors, and SSLS, Inc., March 2008.

${ }^{2}$ A. Stich, H. Varga, C. Neugirg, J. Marfeld, F. Michel. Brilliant Mix - Professional White for General Lighting, Application Note, OSRAM Opto Semiconductors. Available: http://ledlight.osram-os.com/wpcontent/uploads/2009/10/Brilliant_Mix_Professional_White for General_Lighting.pdf

${ }^{3}$ OSLON SSL Ceramic package LA CPDP, LR CPDP, LY CPDP, product datasheet, OSRAM Opto Semiconductors. Available: http://catalog.osramos.com/catalogue/catalogue.do;jsessionid=49B5EF62D837AA1B9CC2A807AA7F9B6F $?$ act=downloadFile \&favOid=0 $\underline{200000400023 e e f 000100 b 6}$ 